研究

Cu-Sn-Pb 系合金の耐摩耗性ならびに而焼付性に及ばす Co 系合金の添加効果

\author{
藤田 正化, 斉藤 康志, 松尾 一雄

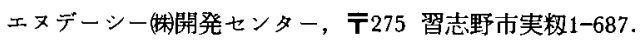

\title{
Effects of Co-Base Alloy Powder Addition on Wear-Resistance and Anti-Seizure Property of Cu-Sn-Pb Alloys
}

\author{
Masahito Fujita, Yasushi Saito and Kazuo Matsuo \\ R\&D Center, NDC Co., Ltd., 1-687 Mimomi, Narashino 275.
}

Received October 23, 1996

\section{SYNOPSIS}

An attempt was made to develop an automotive plane bearing material having improved wear-resistant and anti-seizure properties to meet severe requirements for the greater load and boundary lubrication. Wear-resistant and hard cobalt-base alloy powder up to $7 \mathrm{wt} \%$ was blended in the soft $\mathrm{Cu}-3 \% \mathrm{Sn}-23 \% \mathrm{~Pb}$ matrix alloy powder. The mixture was spread over the backing steel sheet, primarily sintered in the decomposed propane gas, rolled for densifying and secondarily sintered. The cobalt-base hard particles containing molybdenum and chromium are evenly dispersed in the soft matrix. These dispersoids having heterogeneous microstructure lead to hardening of the sintered composite alloy and to improvements in its wear-resistance and anti-seizure property. The wear of shaft is also lightened.

\section{KEY WORDS}

plane bearing, wear-resistance, $\mathrm{Cu}-3 \% \mathrm{Sn}-23 \% \mathrm{~Pb}$ alloy, dispersoids, heterogenity

\section{1 緒言}

$\mathrm{Cu}-\mathrm{Sn}-\mathrm{Pb}$ 系合金は，スチール表層に焼結され，自 動車および一般産業機械の摺動部材料として広く使 われている。特に, 耐荷重性, 耐摩耗性, 而焼付性等 軸受材料とて必要な特性を併せ持つ優れた材料であ る.しかし，この優れた軸受材料を取り巻く環境は， 近年急速に変わりつつある.特に, 従来から潤滑油の 粘度が低く, 境界潤滑に陥りやすい部位や, 給油量が 少なく十分な潤滑が得られていない部位では, 使用 条件の高速, 高荷重化に伴い, 急激な摩耗が発生し, 従来の軸受合金系では，対応しきれない状況が発生 している.こうした境界潤滑下における耐摩耗性の 向上策として従来より青銅, 鉛青銅合金一黒鉛等の 固体潤滑剤の添加、各種硬質物の添加が試みられて
きた 1-6). 本研究では, $\mathrm{Cu}-\mathrm{Sn}-\mathrm{Pb}$ 系合金の中でも特に 耐焼付性に優れる $\mathrm{Cu}-3 \% \mathrm{Sn}-23 \% \mathrm{~Pb}$ 合金（以下\%は wt\%を示す)に, 添加硬質粒子として耐摩耗合金とし て実績がありかつ焼結性の良いCo 基合金を選択し, その焼結体の焼結状態や, 軸受性能を調查した. その 結果Co基合金粉末は，母粉末との焼結性も良くしか も適切な硬さをもっているため, 基地の $\mathrm{Cu}-3 \% \mathrm{Sn}$ $23 \% \mathrm{~Pb}$ 合金の耐焼付性等の軸受性能を損なう事無く, 前記境界潤滑下で優れた耐摩耗性を発揮する事が判 明した。

\section{2 実験方法}

$\mathrm{Cu}-\mathrm{Sn}-\mathrm{Pb}-\mathrm{Co}-\mathrm{Mo}-\mathrm{Cr}$ 系焼結合金の原料粉は、母粉 末として Cu-3\%Sn-23\% Pb合金粉（粒径 $150 \mu \mathrm{m}$ 以下） 
及び添加合金粉としてCo-28\%Mo-8\%Cr合金粉（粒径 $100 \mu \mathrm{m}$ 以下）を使用した。 まず前記母粉末に対し， Co- $28 \% \mathrm{Mo}-8 \% \mathrm{Cr}$ 合金粉が 1, 3, 5, 7,の各 wt \% となる ように秤量し，V型ブレンダーで 30 分混合した。 こ の 4 種類の混合粉及び Cu-3\%Sn-23\%Pb 合金粉（以下 単に $\mathrm{Cu}-\mathrm{Sn}-\mathrm{Pb}$ 合金粉と呼ぶ) のみの粉末を，それぞ れ鋼板製裏金上に $0.80 \mathrm{~mm}$ 厚さに自由散布し,プロパ ン分解ガス䨌囲気中で温度 $810^{\circ} \mathrm{C}$, 時間 30 分の条件 で 1 次焼結した。つぎに, 焼結密度を高めるために, 密度 100\%になるようにロール圧下し，1次焼結と同 じ条件で再度焼結（2 次焼結）を行った.こうして総 厚が $2.20 \mathrm{~mm}$, 合金厚が $0.52 \mathrm{~mm}$ の 5 種類の粉末を焼 結したバイメタル板材を作成した。これらの合金組 成を Table 1 に, 添加合金粉の組成を Table 2 に示す、 また各試料の断面顕微鏡組織, 添加合金粉近傍の

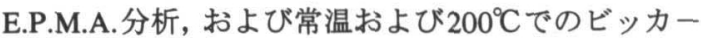
ス硬さを調べた.さらに, 軸受性能をみるために上記 5 種類の材料を円筒状の軸受形状に加工し, ブシュ試 験機を用い耐摩耗性及び耐焼付性を評価した。又そ の時の軸受の初期摩耗の表面状態も調査した.

\section{3 実験結果及び考察}

\section{1 合金断面組織及び E.P.M.A. 分析}

試料（B）および（E）の断面写真を Photo.1に示す. 又 E.P.M.A. を用いて $\mathrm{Cu}-\mathrm{Sn}-\mathrm{Pb}$ 焼結体中に点在する $\mathrm{Co}$ 系合金粉末周辺のE.P.M.A.組成像および界面を横切る ライン分析をPhoto.2および3に示す. 断面組織からは $\mathrm{Cu}-\mathrm{Sn}-\mathrm{Pb}$ 焼結体中に, $\mathrm{Co}$ 系合金粉末が不規則に点在し た状態がみられる.Co系合金粉末はアトマイズ粉であ るため断面形状は丸みを帯び, $\mathrm{Cu}-\mathrm{Sn}$ 素地同士の粒界 や一部 $\mathrm{Pb}$ 粒子に接して分散，焼結している．また E.P.M.A.分析から，Co系合金粉末表面に $\mathrm{Co}-\mathrm{Cr}$ 系化合 物で形成されたスケルトンのみの表面層がみられる. これは, $\mathrm{Cu}-\mathrm{Sn}-\mathrm{Pb}$ 系焼結は $\mathrm{Pb}$ 液相が介在する液相焼 結であり, Co系合金粉末もこの $\mathrm{Pb}$ 液相に表面が濡れ， $\mathrm{Pb}$ 液相を介して焼結が進行する．その結果 $\mathrm{Pb}$ 液相が Co 系粉末表面を浸食し, 表層 Co 基地が流出した事を 示している. また浸食された相の内側にPb相が見られ るのもこうした焼結機構を裏付けている. また,この 表面層自体は強固な構造を持ち, Co 系合金粉の $\mathrm{Cu}-\mathrm{Sn}$ 素地への結合力を損なうものではないと考えられる.

\section{2 合金硬さ}

常温と $200^{\circ} \mathrm{C}$ における $\mathrm{Cu}-\mathrm{Sn}-\mathrm{Pb}$ 素地への Co 系合金 粉の添加量と合金硬さの関係を Fig.1 に示す.Co 系合
Table 1 Chemical composition of test alloys.

\begin{tabular}{|c|c|c|c|c|}
\hline \multirow{2}{*}{$\begin{array}{c}\text { Sample } \\
\text { No. }\end{array}$} & \multicolumn{4}{|c|}{ Composition (wt\%) } \\
\cline { 2 - 5 } & $\mathrm{Cu}$ & $\mathrm{Sn}$ & $\mathrm{Pb}$ & $\begin{array}{c}\text { Co-base } \\
\text { particle }\end{array}$ \\
\hline A & Bal. & 3.0 & 23.0 & 0 \\
\hline B & Bal. & 3.0 & 22.8 & 1.0 \\
\hline C & Bal. & 2.9 & 22.3 & 3.0 \\
\hline D & Bal. & 2.9 & 21.9 & 5.0 \\
\hline E & Bal. & 2.8 & 21.4 & 7.0 \\
\hline
\end{tabular}

Table 2 Chemical composition of Co-base particle.

\begin{tabular}{|c|c|c|c|c|}
\hline \multirow{2}{*}{} & \multicolumn{4}{|c|}{ Composition (wt\%) } \\
\cline { 2 - 5 } & Co & Mo & Cr & Others total \\
\hline $\begin{array}{c}\text { Co-base } \\
\text { particle }\end{array}$ & Bal. & 28 & 8 & $\leqq 3.0$ \\
\hline
\end{tabular}

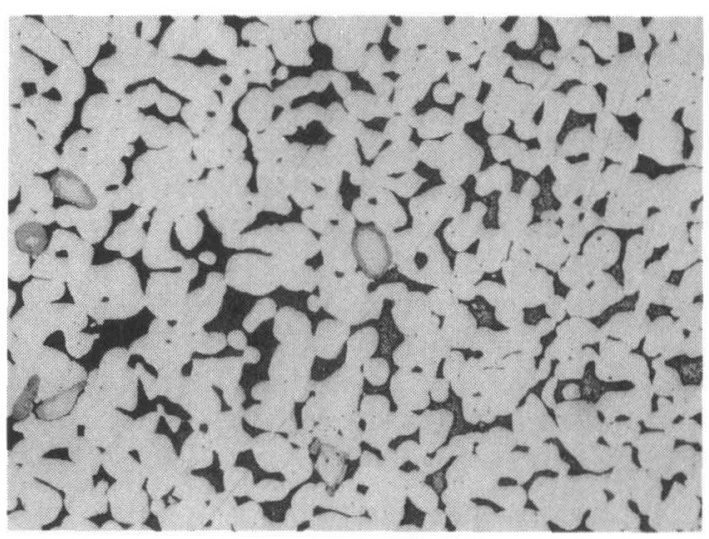

(B) $1 \%$ Co-base alloy

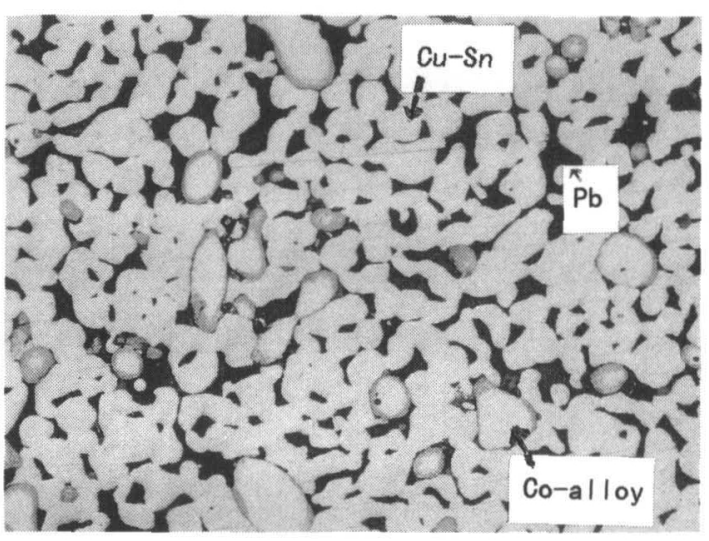

(E) $7 \%$ Co-base alloy

$50 \mu \mathrm{m}$

Photo.1 Typical microstructures of sintered composites. (Cu-Sn-Pb-Co-Mo-Cr system) 


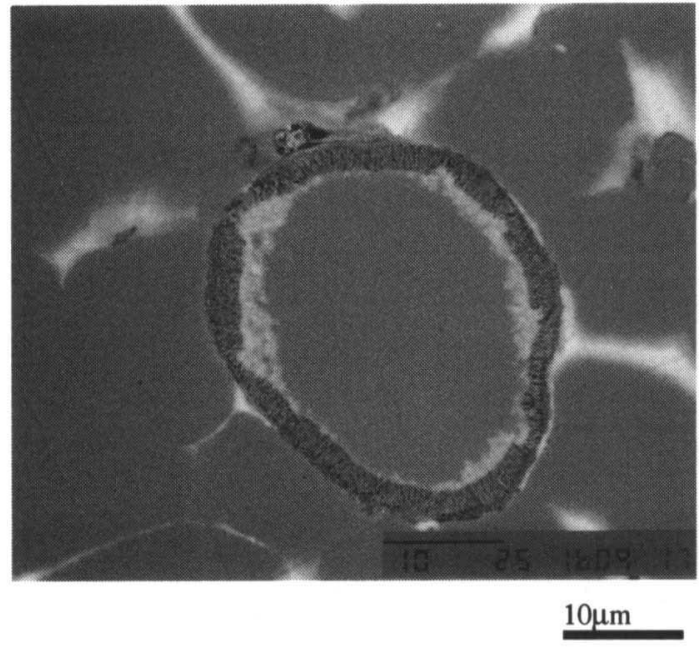

Photo.2 E.P.M.A.Composition.Image of Co-base particle surounded by $\mathrm{Cu}-\mathrm{Sn}-\mathrm{Pb}$ alloy.

金粉末無添加の材料（A）は, ビッカース硬さが Hv58 であり，硬質粒子である Co 系合金粉の添加により一 定の硬度上昇は見られるが, Co系合金粉の添加量に応 じた硬度上昇は見られなかった。これは，今回使用し た Cu-Sn-Pb 合金においては, $\mathrm{Pb}$ を $23 \%$ と多量に含む ため, 硬質粒子添加のマトリックスに与える影響が少 ないことを示している. またこの傾向は高温状態 $(200$ 'C) でも同じくみられた.

\section{3 合金耐摩耗性}

耐摩耗性の評価に用いたブシュ試験機の概要をFig.2 に示す．また試験条件を Table 3 に示す．本試験条件

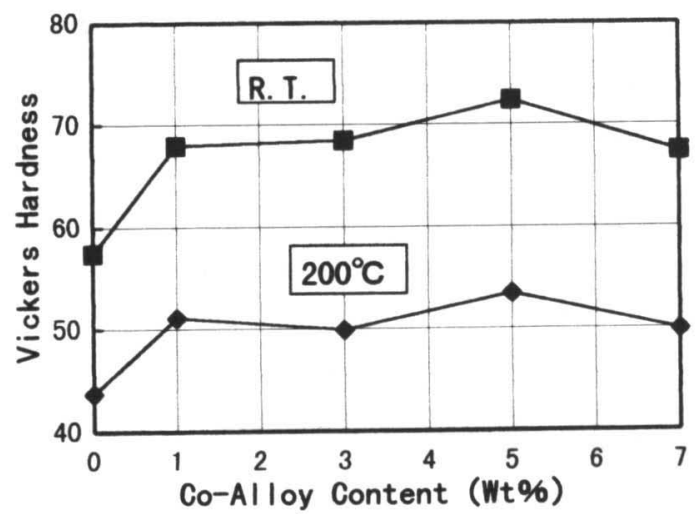

Fig.1 Relationship between vickers hardness (load=1 kgf) and $\mathrm{Co}-$ base alloy content in $\mathrm{Cu}-3 \% \mathrm{Sn}-23 \% \mathrm{~Pb}$ alloy.
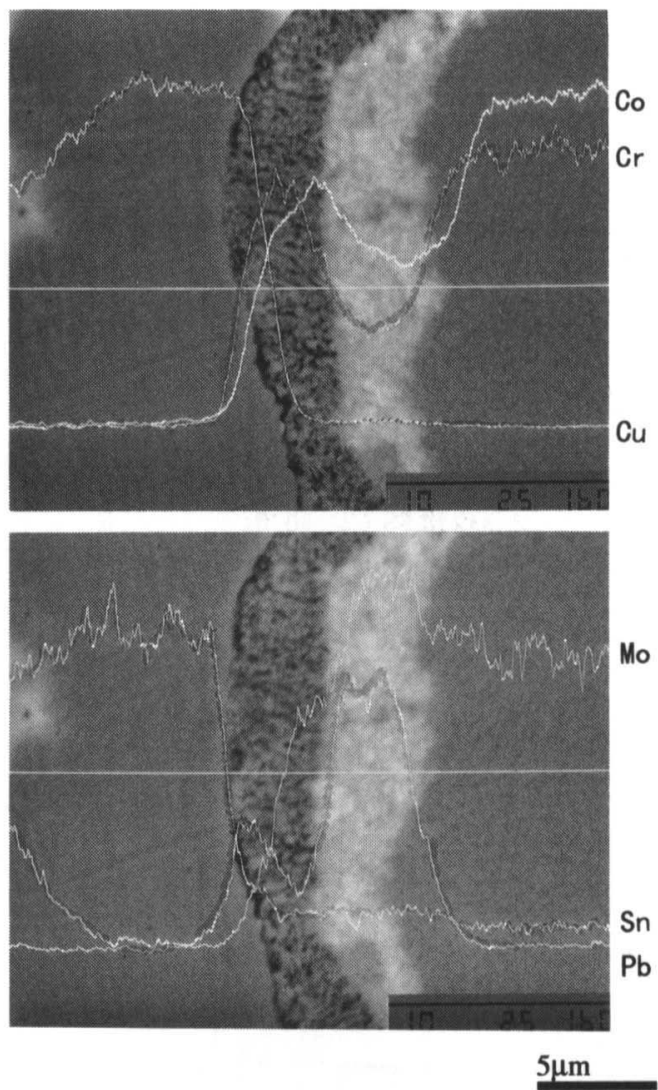

Photo.3 E.P.M.A. line analyses of the boundary magunified Photo.2, between Co-base-alloy particle and $\mathrm{Cu}-\mathrm{Sn}$ alloy.

は, 特に低粘度油による潤滑条件下で, 静荷重をかけ た時の耐摩耗性をみた. 試験後の軸受の摩耗深さは軸 受端面から $3 \mathrm{~mm}$ の両側及び中央部の 3 点の真円度を計 測して, 求めた. Co系合金粉の添加量とこの摩耗深さ の関係を Fig.3に示す. Co 系合金粉を $1 \%$ 添加すると摩 耗量は $1 / 3$ に減少し, $3 \%$ 7\%の添加では $5 \mu \mathrm{m}$ 以下の 摩耗量となる. すなわち, 硬質粒子であるCo系合金粉 の添加により，摩耗量は飛躍的に減少することがわか る.これは, Co 系合金粒子が荷重を支える点となり, 摩耗の進行が, 従来の軟質な $\mathrm{Cu}-\mathrm{Sn}-\mathrm{Pb}$ 合金と軸との関 係からCo 系合金粒子と軸との関係に移行したことを 示している. すなわち, 面で受けていた荷重を, 点で 支える形となり, 潤滑形態が変化したことを示唆して いる、また, 試験後の軸は一部変色が見られたが, 摩 耗等の異常は，見られなかった。

3.4 軸受表面形状の変化

初期摩耗の進行に伴う表面形状の変化について, 
Table 3 Condition of wear test.

\begin{tabular}{|l|c|c|}
\hline TEST CONDITION & DIMENSIONS & UNITS \\
\hline SHAFT DIAMETER & \$20 & $\mathrm{m} \mathrm{m}$ \\
BEARING LENGTH & 15 & $\mathrm{~m} \mathrm{~m}$ \\
LOAD & 2942 & $\mathrm{~N}$ \\
VELOSITY & 0.4 & $\mathrm{~m} / \mathrm{s}$ \\
TEST TIME & 5 & $\mathrm{~h}$ \\
LUBURICANT & KEROSENE & - \\
OIL FLOW & DIPPING & - \\
OIL INLET TEMP & R.T. & ${ }^{\circ} \mathrm{C}$ \\
SHAFT MATERIAL & S45C & \\
ROUGHNESS & 0.8 & $\mathrm{~S}$ \\
HARDNESS & 55 & HRc \\
\hline
\end{tabular}

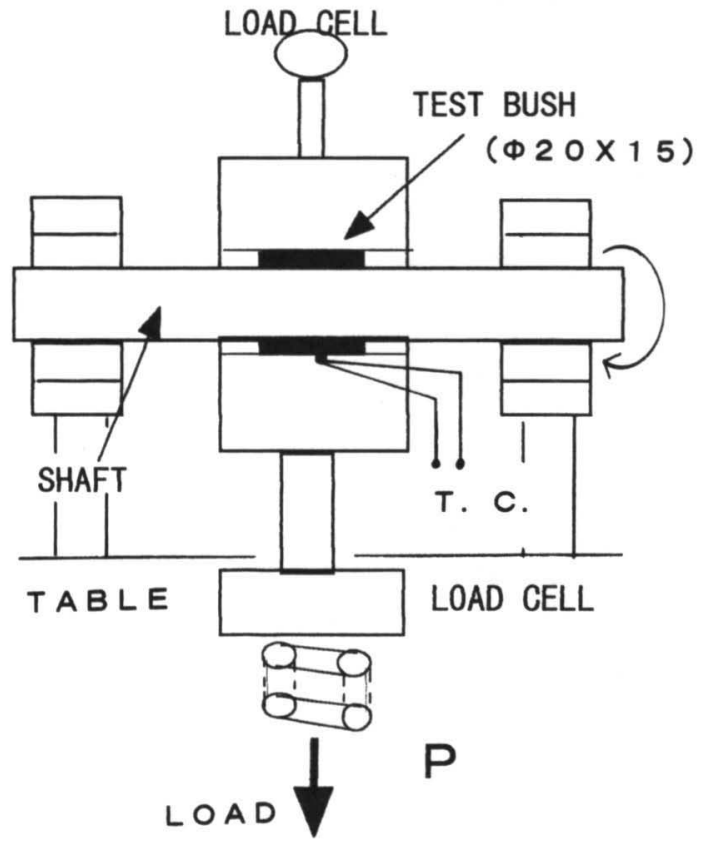

Fig.2 Outline of bushing test machine.

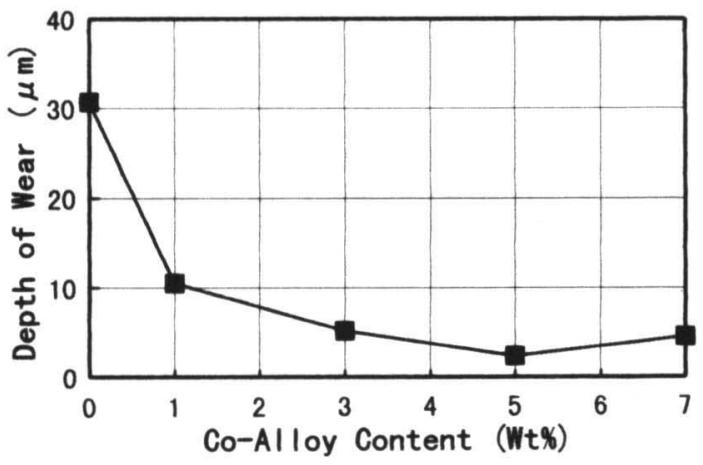

Fig.3 Effect of Co-base alloy content on wear of sintered composite.
$7 \% \mathrm{Co}$ 系合金粉添加材（E）の軸受内面加工後の仕上 げたままの状態から，軸荷重を受けて徐々に摩耗が 進行し粗さが無くなっていく様子を Fig.4に示す.こ の結果から, 当然の事ながら,ある粗さを持った軸受 表面の凸部がまず摩耗してゆくことがわかる. 一方, こうした硬質粒子を含む不均質な材料においては, 内面仕上げ加工時に硬質粒子が，凸部を形成してお り, 従って, 初期摩耗において軸との当たり面が次第 になじんで平滑化してゆく段階で，硬質粒子と軸と の摩擦摩耗の関係が先行して発生することになる. すなわち安定したなじみ面が軸受性能を保持しなが ら, 耐摩耗性を持つ表面として成立するためには, こ の先行して生じる軸（Fe）とCo系合金粒子の摩擦摩 耗の関係が, 良好な状態を保つ必要があるといえる.
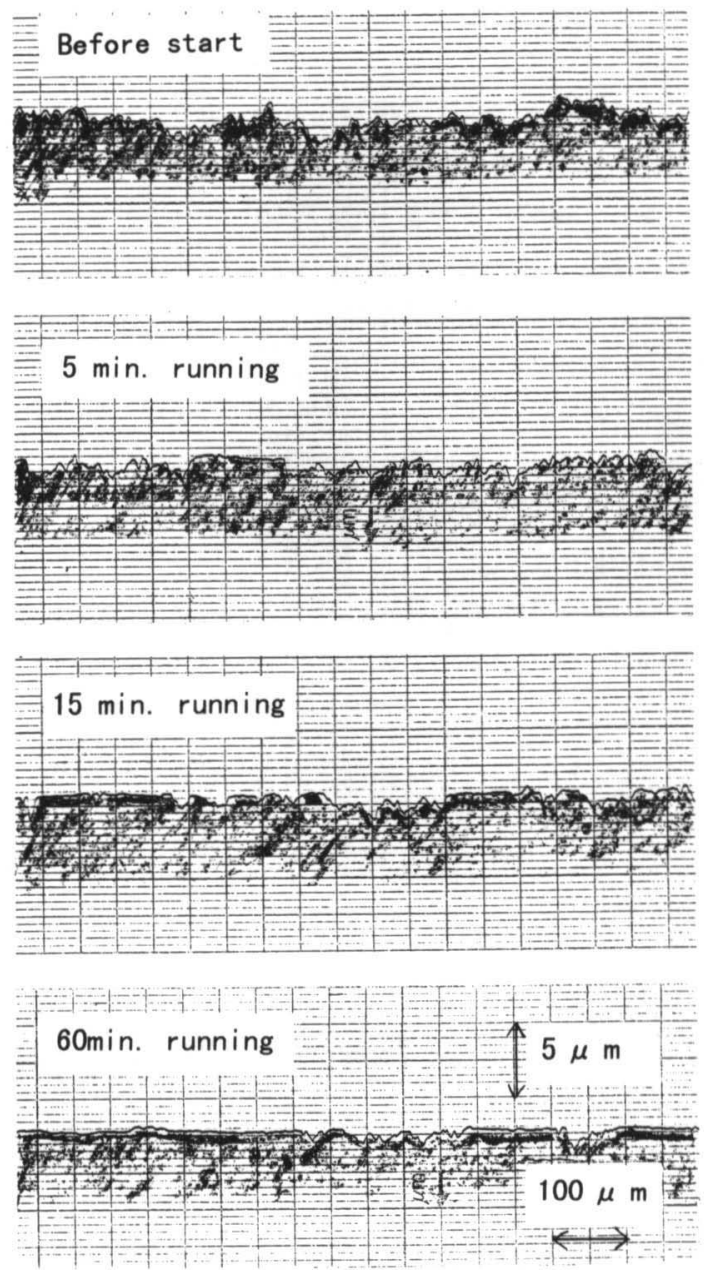

Fig.4 The change of face profile with progress of initial wear. (7\% Co-base alloy composite) 


\section{5 合金酎焼付性}

Table 4 に耐焼付性をみた試験条件を示す．尚，こ の試験においても, Fig.2に示すブシュ試験機を用い た.また，焼付条件として馴らし運転の後，潤滑油を カットし,その後, 軸受背面温度が $200^{\circ} \mathrm{C}$ に達した所 で焼付とした.使用した潤滑油は, 自動車のトランス ミッション等に使われるATF油とした。本試験では, Co系合金粒子を含まない基材 (A) と $5 \%$ 添加材 (D) の2種の合金を比較し Fig.5 に示す. その結果 Cu-Sn$\mathrm{Pb}$ 合金のみの合金 (A) は, 171秒で焼き付いたのに 対し，Co 系合金粒子を $5 \%$ 含む材料は，3600秒たっ ても焼村の兆候が見られず, 途中で停止させた.この 様に焼付性能においても，Co 系合金粒子添加は優れ た勃果を示し，良好な軸／Co 合金の摩擦摩耗の関倸 が耐焼付性能の向上にも寄与していることを示して いる.すな放焼付現象の初期の段階は軸と軸受け の金属接触の結果, 軸表面に軸受合金が移着し更に 軸受合金自体が破壊してゆく凝着摩耗が進行してゆ く段階である。ここで硬質な化合物を含むCo 系合金 粒子の軸受合金への添加は, 軸への軸受合金の移着 を防止する効果を生み凝着摩耗を防止し耐焼付性の 向上に寄与したものと考えられる.

Table 4 Condition of seizure test.

\begin{tabular}{|l|c|c|}
\hline TEST CONDITION & DIMENSIONS & UNITS \\
\hline SHAFT DIAMETER & Ф20 & $\mathrm{m} \mathrm{m}$ \\
BEARING LENGTH & 15 & $\mathrm{~m} \mathrm{~m}$ \\
LOAD & 1000 & $\mathrm{~N}$ \\
VELOSITY & 5 & $\mathrm{~m} / \mathrm{s}$ \\
TEST TIME & UNTIL BBT $200^{\circ} \mathrm{C}$ & $\mathrm{h}$ \\
LUBURICANT & A T F & \\
OIL FLOW & DIPPING $\rightarrow$ CUT & \\
OIL INLET TEMP & 120 & ${ }^{\circ} \mathrm{C}$ \\
SHAFT MATERIAL & SCI42OH & \\
ROUGHNESS & 0.8 & $\mathrm{Z}$ \\
HARONESS & 65 & HRC \\
\hline
\end{tabular}

Seizure Time (sec)

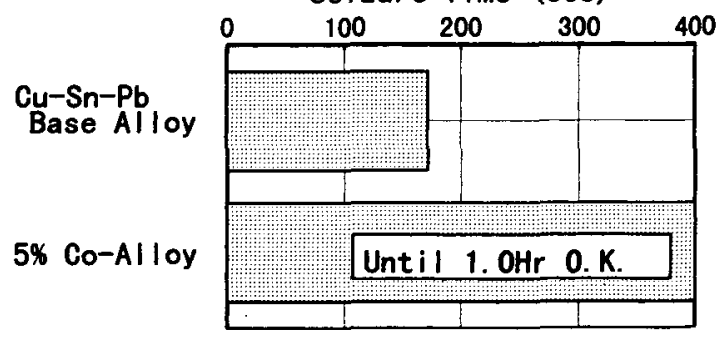

Fig.5 Seizure time of Cu-3\%Sn-23\% Pb alloy and 5\%Cobase alloy composite.

\section{4 結 言}

$\mathrm{Cu}-3 \% \mathrm{Sn}-23 \% \mathrm{~Pb}$ 合金粉に耐摩耗材として，硬質な Co系合金粉末を混合し焼結することによって得られ た合金の特性を調查した結果は，以下の通りである.

(1) $\mathrm{Cu}-3 \% \mathrm{Sn}-23 \% \mathrm{~Pb}$ 合金粉にCo系合金粒子を均一に 分散焼結する事が可能で，本焼結により合金硬度が 增加する。

(2) Co 采合金粒子を添加すると，無添加の合金に比 べ、耐摩耗性，ならびに耐焼付性が向上する。これ は, マトリックス中のCo 系合金粒子と軸との摩擦摩 耗の関係が極めて良好な事を意味する.またこの時, 軸の損耗は見られなかった。

\section{文献}

1) 新見義郎, 是川宏,岩津修: 粉体および粉末治金, 34 (1987) 264 .

2) 特許, 特公昭 57-50844.

3) 特許, 特公平 7-62191.

4) 唃口月光,山本康一,坂本雅昭: 粉体および粉末治 金, 40 (1993) 780 .

5) 特許, 特公平 8-3133.

6) Akira Fujiki,Makoto Kano: Metal Powder Report, Jan., (1995) 26. 